\title{
2 \\ Closing the gap between regulation and the community
}

\author{
Valerie Braithwaite
}

\section{Introduction: Regulation - from social dread to social 'cred'}

For most people, 'to regulate' means to control or direct others by rules or standards. The term can carry negative baggage, particularly when attached to government. Rightly or wrongly, government regulation has connotations of a powerful authority 'making' people do things they would not otherwise do and generally interfering in people's lives in intrusive and wasteful ways.

Regulation need not be this way. First, it need not be dominating. We can agree to regulation and participate in it. Second, it need not involve government. In an era where governance is global and nodal, we find ourselves being regulated by international bodies, professional associations, trade agreements, markets, private industries, local entities and even event organisers unknown to us. And third, regulation may of course serve a useful and important function for the community. It may enhance wellbeing - as through quality standards in health care, education, food, water and housing-provide consumer protection and safeguard our security and rights. 
So why do we hear the word regulation and think bureaucratic overload instead of valuable community oversight? If regulation has been giftwrapped as Pandora's box to which government alone holds the key, it is time for us to undo the wrapping and be part of the conversation about the contents of the box and how to best manage its harms. As a social activity that includes persuasion, learning, praise, emulation, self-regulation, influence, voluntary compliance, along with its usual companions, deterrence and coercion, the term 'regulation' might lose its mystery and remoteness. We can recognise regulation as something we all engage in when we intervene purposefully in any social world.

As social beings, our acts of regulation are endless. On a daily basis, we shepherd each other at home, school, work and play: holding a child's hand when crossing a road, giving others feedback on their written work, complimenting a person on a job well done, showing appreciation of another's thoughtfulness, reciprocating a favour or offering advice to a person in distress. New forms of formal regulation should never be about undermining the social fabric that regulates effectively. The purpose should be to strengthen the useful aspects of informal regulation that are already in play, complementing, not undermining, them. So, for instance, we teach a child to watch the traffic lights as we cross a road, we assess and review papers to improve their quality, we have awards for excellence in performance and extraordinary acts of kindness, and we have help lines and emergency numbers to phone for assistance. None of these regulatory measures weakens the natural systems of social regulation already in place. Rather, formal regulatory measures build on the informal. They become a welcome part of the flow of everyday life because they are judged to add value.

Looking at regulation through a social lens may seem to some to miss the mark, given the many regulatory activities we witness occurring at a distance from human beings. Simple regulatory measures in this category include building pathways, gates and walls. More sophisticated examples are the technological surveillance of money transfers, tracking devices on aircraft, withholding pension payments from wages, income management within social security systems, satellite imaging of vegetation and forest degradation, desk analyses of big data, paper trails and record keeping and the highly technical, complex and voluminous tax code. Such hightech approaches combined with intricate design rules that allow only an elite to understand the game makes 'the social' in regulation seem quaint, if not entirely the wrong genre for analysis. 
It is important, however, to differentiate mechanism from purpose. Mechanisms at times may be devoid of the social, being impenetrable and invisible to us. Yet their purpose may be deeply social and have farreaching consequences for a society. The use of drones to drop bombs in war zones is distant from us. They are the weapons of politicians, though they may also deny responsibility with a moral defence of distance. Drones are highly sophisticated, 'thinking' machines that do their jobs devoid of human intervention. The consequences, however, may involve the destruction of towns and villages, and the loss of civilian lives. The consequences are not only highly social, but also political. 'Human hands-off' technology may destroy not only societies and culture, but also international cooperation and trust. So-called asocial interventions change the social fabric and relationships beyond the zones in which they operate. Regulatory purpose, as Christine Parker and John Braithwaite (2003) express it, is to steer the flow of events. Steering at some point takes place through, or impacts on, people; people at some point become aware of changes in the flow of events, they give meaning to events and meaning plays an important role in determining regulatory outcomes, not only on that occasion but also in future.

\section{An example: Higher education in Australia}

Australia's higher education contingent loan scheme provides a fitting example of why shared meanings of regulation in the community are important. The Australian Government replaced free tertiary education in 1989 with a scheme whereby government paid universities for a student's tuition through a loan, which was to be repaid by the student when her income exceeded a certain level. Policymakers hailed it a brilliant regulatory strategy. The idea was exported to other countries, including the United Kingdom. The public, however, did not agree, as Eliza Ahmed demonstrated in a series of analyses of tax and loan repayment (Ahmed and Braithwaite 2004, 2005, 2007; Braithwaite and Ahmed 2005). Students who considered the scheme unjust and who were less than satisfied with the education they received acted out their grievance through shifting the focus of their retribution from the government to the tax system. The tax system, used to collect the Higher Education Contribution Scheme (HECS) debt, became the target of abuse for work-related expenses and undeclared income. This was a paradoxical regulatory result given that a rationale for abolishing free higher education was that the public was said to be unwilling to pay higher taxes for free education for their children. 
This tax blowback was symptomatic of trouble to come. The government's attempt to reform the tertiary sector in 2015 collapsed, with the feared cost of tertiary education fees being no small part of the community backlash. A lost Arcadia of free tertiary education lay dormant as a benchmark and high point of Australia's tertiary education systemnot according to the technocrats of Treasury and higher education policymaking, but in the meaning ascribed to it by ordinary Australians. Free tertiary education meant a fair go and equal opportunity for one's children and grandchildren.

The interpretation and meaning given to regulation by those being regulated may not match that of regulators. If the gap in sense-making is associated with low trust, cooperation may be jeopardised. Cooperation does not guarantee regulatory success, but it helps. Cooperation and willingness to comply are most likely to occur if those being regulated see benefits, believe the regulation is fair and feel a sense of obligation to defer to a regulating authority's wishes. It also helps if alternative authorities (for example, peak bodies or international organisations) endorse the regulator's efforts and do not lead a campaign to steer the flow of events in different directions. These dynamics are all part of the compliance process in a democratic society.

\section{Foundation concept: Compliance as process}

Compliance has two usages: outcome and process. First, it may represent an outcome of a regulatory intervention. Did the regulated party do what was required according to law or the demand of the regulator? Was a tax return filed on time at the behest of a tax authority? Was a restraining order adhered to at the behest of the court? Was a security alarm activated in a building at the behest of an insurance company? Was a car securely locked? Were dietary restrictions adhered to at the behest of a doctor? Compliance as outcome tends to be specific, behavioural and measurable.

Compliance as process is a broader, relational concept. Compliance as process bridges the world of the regulated and the world of the regulator. From the perspective of the regulated, it incorporates our understanding of what an authority wants us to do, the purpose behind the regulation, 
whether or not we agree with it, how we evaluate implementation of the regulations and what our attitudes and behavioural intentions are with regard to the regulatory request and the authority.

From the perspective of regulators, compliance as process asks what effort has a regulatory authority made to elicit compliance and what have alternative authorities been doing: contesting the actions of the lead regulator or endorsing them? How regulators and regulatees view each other and negotiate the compliance space is relevant not only to compliance as outcome, but also to the future legitimacy and trustworthiness of the regulatory system more generally.

Compliance as process involves mapping the regulatory actors in what Meidinger (1987) calls the 'regulatory community'. A regulatory community comprises different subcultural groups with their own values, norms, beliefs and processes. Through their leaders, they may undermine regulatory authority or extend its reach. They use their networks and alliances to push back and shape the actions of the regulator, just as the lead regulator uses its power and authority to steer the flow of events in the direction it wants.

\section{Freedom, respect and procedural fairness: Regulatory principles to live by}

The RegNet community philosophy has always been to respect pushback wherever it comes from. This is why compliance as process has such appeal in our work. We do not assume that those with power always have it right. And we do not assume that regulation is the answer to all social ills. Indeed, Peter Grabosky's (1995) work on unintended consequences demonstrates how the best of intentions in regulation can go horribly wrong. Debate and contestation over what regulation might achieve and how best to regulate in the context of democratic governance are at the core of our conception of good regulatory practice.

Two meta-principles have guided our work in RegNet. The first is to use regulation sparingly, introducing formal regulation only when it is necessary as a means of structural reform to further the Republican principle of 'freedom as non-domination' (Pettit 1997). The right kind of regulation is that which reduces the amount of domination (increases the quantum of freedom) in the world (J Braithwaite et al. 2007). 
The second meta-principle is consistent with the first, but focuses specifically on how a regulatory system should operate and how regulators should engage with the community - that is, with respect and procedural fairness (see Murphy, Chapter 3, this volume).

Freedom as non-domination, respect and procedural fairness are held as desirable principles in their own right. They also serve another function. When regulations are designed following these principles, cooperation and voluntary compliance are likely to be higher and fewer parties are likely to need coercive measures to comply.

This approach should be tantalising for a regulator: a regulatory system that runs essentially on goodwill with regulatory effort dedicated to the recalcitrant few. Why should this not be the normal experience with government regulation? Globally, workplaces mostly manage to run this way. Locally, families do, too. How, then, can we replicate this across our society?

\section{Regulating well: The wheel of social alignments}

One way of thinking about how to turn this aspiration into a practical implementation plan is through the wheel of social alignments represented in Figure 2.1.

The wheel of social alignments was developed by the author to guide regulatory conversation and responsiveness in the regulatory community. The model grew out of work in the Centre for Tax System Integrity (CTSI, 1999-2005) undertaken by Eliza Ahmed, John Braithwaite, Nathan Harris, Kersty Hobson, Jenny Job, Kristina Murphy, Greg Rawlings, Declan Roche, Yuka Sakurai, Natalie Taylor and Michael Wenzel. The work of the centre challenged traditional deterrence theory as the approach best suited to understanding tax compliance. The odds of detection and penalties were so low that it was rational to cheat on tax, yet most people did not. The CTSI research focused in particular on the importance of the social-psychological determinants of compliance: norms, values, identity, shame, guilt and trust (Braithwaite and Wenzel 2008). 


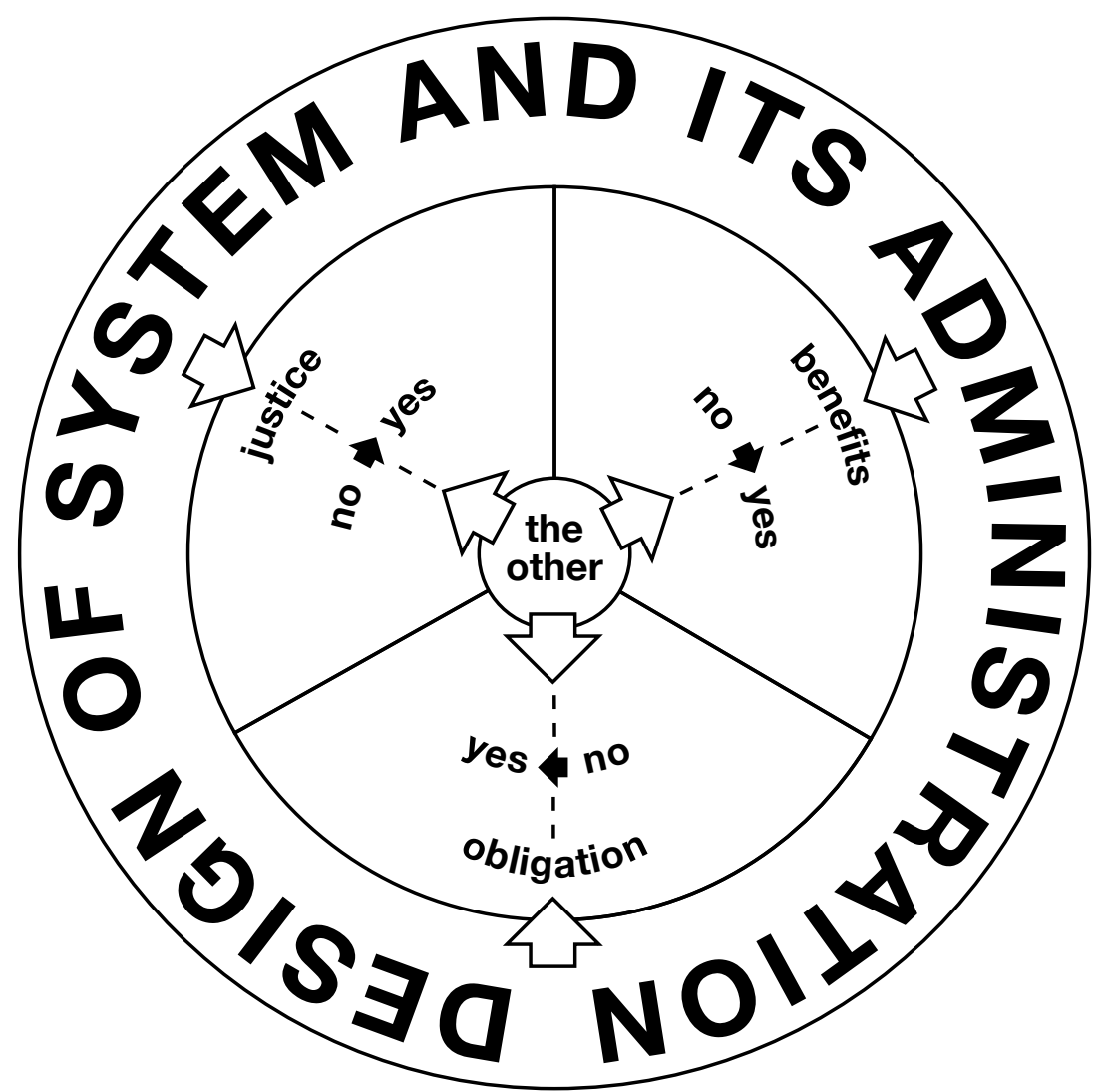

Figure 2.1 Tracking the process: Wheel of social alignments Source: Author's research.

The wheel integrates the results of this work into bands and segments that a regulatory authority needs to monitor systematically if they are to regulate in accord with the democratic and republican meta-principles above.

The outer band of the wheel represents the design of the regulatory system. This part sets out the legislation, guidance for interpretation and policy intent, investigative rules and enforcement practices, principles of governance and administrative practices. The outer band incorporates the activities of the regulator and the base from which the regulator works. 
The middle band represents how those who are being regulated evaluate what is being asked of them and the primary factors shaping compliance. Conflict with authority is most likely to arise around the failure of regulations to: 1) provide benefits; 2) ensure justice; and 3) elicit moral obligation. Michael Wenzel provided an extra dimension to these considerations through demonstrating that each of us identifies with our own interests, as well as with the interests of the many groups to which we belong. Depending on our level of identification at the timefrom personal to national-our evaluation and discussion of benefits, justice and obligation change. Regulatory leadership is necessary to convince us which collective identity we should put forward to facilitate collective action.

If leadership is not forthcoming and we remain unconvinced of the value of the regulations for the community, even if not for us personally, we may turn to other sources for advice. The inner core of the wheel represents 'the other'-the significant voices or nodes of influence that shape our views and to which we turn to formulate a regulatory response. 'The other' in the regulatory community thereby can take on the role of an alternative authority. The role is strengthened when there is confusion, uncertainty, dissension and loss of trust in the system as represented by the outer circle in Figure 2.1. For taxpayers, the alternative authority may be aggressive tax planners; for young disenfranchised Muslims, it might be Islamic State; for unskilled, marginalised workers engaging in unsafe work practices, it may be their hire company or recruitment agency.

The width of the three bands in Figure 2.1 indicates the degree of dialogue and contestation, and varies with culture and context. The inner core and middle band are likely to be relatively wide when regulators must rely on public cooperation, as is the case with anti-littering laws or safe work practices. When a regulatory system is imposed 'invisibly' without opportunity for noncompliance, the outer band will be wide, leaving the middle band and inner core empty, bereft of dialogue and contestation. This was the case with the collection of metadata and surveillance of private phone calls and emails by the US Government, until the revelations of Edward Snowden in 2013.

The central idea of the wheel of social alignments is that when the parts in Figure 2.1 work harmoniously together, the wheel moves forward. When one part separates from the others, the wheel comes to a stop or is difficult to move until repaired through dialogue, responsiveness 
and regulatory leadership. The greatest risk to forward momentum is defiance by individuals or groups who form alliances to confront the regulatory authority with its failings. Examples of alliances of defiance that demonstrate 'the strength of weak ties' (Granovetter 1973) in the regulatory context include the Boston tea party, with its chants of 'no taxation without representation' (1773), Australia's Eureka Stockade (1854), Gandhi's Salt March in India (1930), the 1960s US civil rights movement, Nelson Mandela and the African National Congress's fight against apartheid in South Africa through the second half of the twentieth century, Czechoslovakia's Velvet Revolution (1989) and, more recently, public protests against police brutality in the United States.

\section{Responding to authority: Defiance and motivational postures}

Defiance can be understood not only as an act of combustible contrariness, but also as a premeditated response when a regulatory authority threatens identity. Authority threatens by virtue of being an authority - an entity that can take away one's freedom to act as one pleases. From the moment of birth, we learn to cope with authority: parents, teachers, work bosses, an array of professionals whose role is to advise and care and officials from the government and private spheres. We are well practised in dealing with authority that exercises control over what we do.

Motivational postures refer to the signals or messages that we send to authority about the control it purportedly has over us. Motivational postures are sets of beliefs and attitudes that sum up how individuals feel about and wish to position themselves in relation to authority: they communicate social distance. Social distance has two aspects: liking and deference. Liking and deference often go together, but not always. Theoretically, they are distinct. I may like and admire my supervisor in the sense that I have positive emotions towards her, but I may not always defer to her judgement of how I should progress my career. I may judge her not to be an authority on what is best for me. On the other hand, I may defer to her judgement on every occasion because of her capacity to help me further my career, but I may not particularly like or admire the way she operates. In other words, we may be satisfied with and approve of an authority, but not defer to the requests it makes of us. Or we may defer, but not think well of the authority to which we are deferring. 
The five motivational postures are empirically derived. We have found that people adopt these postures in many different areas of regulation, from aged care regulation and taxation to the regulation of civil wars (J Braithwaite et al. 2007, 2010; V Braithwaite 2009). First, we may display the posture of commitment- that is, we may communicate to the authority that we believe it has a worthy mission and we feel duty bound to support its work. Or we may recognise the authority, but be somewhat less enthusiastic or agnostic about what it does. That is, we may signal capitulation: 'Tell me what you want of me and I will do it; you're probably legitimate and I don't want trouble.'

Both commitment and capitulation are postures of accommodation to authority. In a democracy, both tend to be strong. Regulatory bodies that do not command support from a critical mass do not last long, as Bernstein (1955) observed in his study of US railway commissions. Railway commissions were legal entities with specialised knowledge that sought to emulate the impartiality and political aloofness of the judicial system. Their complexity and remoteness, however, meant that outsiders lost sight of their purpose and value, and they were dissolved.

In addition to accommodating postures, we may signal defiant postures. We often mix them, hedging our bets in a bid to be self-protective in case the threat from authority escalates. The most common defiant posture is resistance. Resistance is healthy in a democracy and signals dissatisfaction with how the authority is doing its job. Resistance, more than any other, is a plea to authority to be fair and respectful. Authorities manage resistance successfully when they introduce greater procedural fairness into the way they operate (see Murphy, Chapter 3, this volume).

Two other defiant postures are less common, but far more threatening to regulators. They are postures that are adopted by those who refuse to defer to the authority's rule. They are postures of dismissiveness. The first is disengagement, in which social distance from the authority is greatest. Disengagement involves neither attending nor responding to the authority, but rather continuing business as usual. Disengagement mirrors Merton's (1968) construct of 'retreatism': 'in the society but not of it'. The final dismissive posture of game playing takes place in an adversarial space where the regulator is being watched carefully and the objective is winning against the rules. Game playing involves searching for loopholes and ways around the regulatory authority, undermining the authority's effectiveness and its legitimacy. 
Postures of accommodation and defiance ebb and flow in all of us and provide regulators with a complex, ever changing set of signals to decipher. It is in response to this challenge that the wheel of social alignments is useful. It reminds regulators to reflect on their own mission and practice and ask if they have all the pieces in place to have earned postures of commitment and capitulation from the public, if they have the institutional mechanisms in place for hearing resistance and responding respectfully and constructively to it and if they have accurately assessed the root causes of disengagement and game playing.

Dealing with disengagement and game-playing, both of which have been empirically related to law violation, seriously challenges an authority's enforcement capacity and legitimacy. The battle here is not about procedural fairness since postures of disengagement and game playing are adopted by those individuals or groups who have no respect for the regulatory institution and expect none in return. The battle is about moral authority: what is the right thing to do (and who has the power to decide)? This requires the force of the law, credible enforcement and society's backing to add normative moral gravitas to the debate.

\section{What shapes motivational postures? World views and three selves}

Motivational postures sum up our feeling about and responsiveness to authorities. They are shaped in part by stable world views. It is unlikely that wildlife traffickers hold accommodating postures to the World Wide Fund for Nature when it supports local governments in the fight against illegal trafficking. Similarly, supporters of civil liberties are unlikely to adopt accommodating postures to government keeping records of private phone calls and internet usage. In the field of tax compliance, we find that those disillusioned with the democracy feel less obliged to pay tax, as do those who believe in small government and free markets. Those who look to government to care for the vulnerable, on the other hand, willingly pay tax.

While values and world views are important, so, too, are contextual variables. Credible enforcement matters in so far as it signals an authority's (and society's) belief that compliance matters: it is not just obeying rules; it is the right thing to do. When costs and benefits are being weighed up 
in a rational or pseudo-rational manner, credible enforcement sways the ledger in the direction of compliance rather than noncompliance, and in the direction of the more accommodating motivational postures.

Just as important as deterrence is how a regulatory authority manages the wilfulness of potential noncompliers. Shame and guilt are powerful emotions for driving compliance (see Harris, Chapter 4, this volume). But when regulators set out to publicly shame regulatees in a stigmatising way, they risk a regulatory stalemate. Stigmatising shaming by authority is likely to induce humiliation and set in train social ostracism. Those affected are likely to express their anger and grievance through fighting back, inflicting reputational damage on the regulator in the process (V Braithwaite et al.2007). This is why procedural fairness, whatever the regulatory breach happens to be, is so important as part of a regulator's standard operational procedure. The regulatory purpose is to change the harmful behaviour and not be diverted into reputational battles, as Kristina Murphy $(2004,2005)$ describes in her research on Australian taxpayers. In 1998-99, many were caught in mass-marketed schemes that the Australian Taxation Office judged to be tax-avoidance products, peddled by promoters in the financial planning industry.

Nathan Harris (Chapter 4, this volume) discusses the role of guilt and shame in regulation, but equally important is the role of pride. Eliza Ahmed's work apprises us of how important pride is in a regulatory context, particularly 'humble pride' (Ahmed and Braithwaite 2011). Ahmed draws a distinction between humble and narcissistic pride. Narcissistic pride occurs when individuals garner success to put themselves above others, to be superior and dominate others. Humble pride is about self-respect for our achievements and inner satisfaction, while acknowledging our social infrastructure and its support. Humble pride allows us to be socially in tune with others and is responsive to quiet acts of appreciation and acknowledgement of effort by others that help us achieve success. Recent work on regulating through supports as well as sanctions (Healy 2011) targets our humble pride, recognising and thereby reinforcing our inner belief in our goodness, competence and self-efficacy (Bandura 1986; Jenkins 1994).

Whenever we are faced with a regulatory imperative-as individuals or groups-threat lies in the background. Emotions therefore are triggered as well as reason. One way of thinking about our inner psychic battles when a regulatory agency makes its presence felt is in terms of three selves that step forward to analyse or make sense of the potential threat 
for us. There is the moral self that assures us we are good, competent and law abiding, and that the best course of action is not to be afraid, but rather to tend and befriend the regulator. Safety lies in working with the regulators. Then there is the grievance self, the self that feels oppressed and unappreciated, and threatened by impending unreasonable demands and acts of injustice. The grievance self is a threatened self that needs reassurance and support. The third self is the status-seeking self. This self overcomes and solves problems, determinedly pursuing a path of personal achievement and ensuring no real regulatory threat materialises.

These three psychological selves explain how postures ebb and flow. Motivational posturing theory posits that the defiance of resistance comes about when our grievance self is strong, possibly triggered by disrespect from the regulator, and our moral self is weak, possibly left to wither on the vine by the regulator. In contrast, the defiance of dismissiveness of authority (involving disengagement or game playing) pits a strong status-seeking self against a weak moral self.

These three psychological selves reinforce the regulatee's segments in the wheel of social alignments: provide benefits, to be mindful of a statusseeking self; ensure justice, to be mindful of the grievance self; and elicit moral obligation, to be mindful of the moral self. Offending any or all of these selves is likely to make the task of regulating without constant surveillance and coercion extremely difficult.

\section{Conclusions: 10 things to know and 10 questions to ask}

Ten principles follow from looking at micro-macro regulation through a social-psychological lens and they trigger important regulatory questions for conversation in the regulatory community:

1. Understand that people view a regulatory authority as a potential threat to freedom and wellbeing. This threat exists for those who break the law and those who do not. How is the threat being interpreted by different segments of the community?

2. Know the regulatory objective. Is the purpose to punish or alienate or is it to elicit a substantive improvement and cooperation in the future? 
3. Be open and responsive to cases of hardship. Is this individual or organisation being burdened or limited in unexpected and unfair ways by regulation?

4. Deliver procedural justice by treating those being regulated with respect, have clear and transparent procedures and provide reasonable and fair hearings for dissidents. Are various segments in the regulatory community experiencing regulation as an unfair and unreasonable imposition because they see no mechanism for change and are denied a voice in stating and resolving problems?

5. Engage constructively with dissenting voices. Have the regulator and other relevant authorities got it wrong, and is there a better way of dealing with a harm that everyone acknowledges is there?

6. Engage with dissent in terms of social justice. Do the outcomes of the regulation benefit everyone or are the costs and benefits of regulation born disproportionately across the regulatory community?

7. Engage with dissent on moral grounds. Is it right morally to steer the flow of events in the way proposed?

8. Provide hope for the future through recognising and praising strengths openly. Are there acknowledgements and rewards in the system that are set up in such a way as to strengthen internal resolve to achieve the goals of the regulatory system and encourage humble pride among others to do likewise?

9. Return to the scene of noncompliance and reengage with regulatory interventions. Is there a restorative justice and responsive regulatory framework that can be used to simultaneously build commitment to the regulatory system and achieve compliant outcomes?

10. Build networks within the regulatory community to ensure clear communication and exchange of views and information. Will alternative authorities be willing to support the regulator with enforcement challenges or will alternative authorities act as countervailing forces?

These 10 principles and questions emerge from seeing regulation through a social-psychological lens. We have engaged with regulation in this chapter as a set of social institutions that coordinate communities-individuals and organisations alike-with respect and with the minimum amount of intrusion required to redress harms of domination by some that undermine the freedom of others to pursue their hopes and dreams. Seeing regulation in this way may demand 
a quality of social nuance in government that is unusual on the world stage these days. But as people turn to a philosophy of individualism to give their life meaning and purpose, as trust in democratically elected governments continues on a downward slide and as alternative authorities see a power vacuum and extend their influence, there seems little option for us collectively but to place our hopes in a transformation where governance and regulation are openly contested and regulatory measures are agreed to with eyes wide open. In other words, the time may have come for a genuine effort to regulate responsively and transparently with inclusion of the nation's residents and citizens. It is time for us together to open this Pandora's box and let hope out.

\section{Further reading}

Ahmed, E, Harris, N, Braithwaite, J and Braithwaite, V 2001. Shame Management through Reintegration. Cambridge: Cambridge University Press.

Braithwaite, V (ed.) 2003. Taxing Democracy: Understanding Tax Avoidance and Evasion. Aldershot, UK: Ashgate.

Braithwaite, V (ed.) 2004. 'Hope, power, and governance', The Annals of the American Academy of Political and Social Science 592: 6-17.

Braithwaite, V 2014. 'Defiance and motivational postures', in D Weisburd and G Bruinsma (eds), Encyclopedia of Criminology and Criminal Justice. New York: Springer Science \& Business Media, pp. 915-24. doi.org/10.1007/978-1-4614-5690-2_61.

\section{References}

Ahmed, E and Braithwaite, J 2011. 'Shame, pride and workplace bullying', in S Karstedt, I Loader and H Strang (eds), Emotions, Crime and Justice. Oxford: Hart Publishing, pp. 55-80.

Ahmed, E and Braithwaite, V 2004. 'When tax collectors become collectors for child support and student loans: Jeopardizing the revenue base?', Kyklos 57(3): 303-26. doi.org/10.1111/j.00235962.2004.00256.x. 
Ahmed, E and Braithwaite, V 2005. 'A need for emotionally intelligent tax policy: Linking tax evasion with higher education funding', Legal and Criminological Psychology 10: 291-308. doi. org/10.1348/135532505X37263.

Ahmed, E and Braithwaite, V 2007. 'Higher education loans and tax evasion: A response to perceived unfairness', Law \& Policy 29: 121-36. doi.org/10.1111/j.1467-9930.2007.00249.x.

Bandura, A 1986. Social Foundations of Thought and Action: A Social Cognitive Theory. Englewood Cliffs, NJ: Prentice-Hall.

Bernstein, MH 1955. Regulating Business by Independent Commission. Princeton, NJ: Princeton University Press. doi. org/10.1515/9781400878789.

Braithwaite, J, Braithwaite, V, Cookson, M and Dunn, L 2010. Anomie and Violence: Non-truth and Reconciliation in Indonesian Peacebuilding. Canberra: ANU E Press.

Braithwaite, J, Makkai, T and Braithwaite, VA 2007. Regulating Aged Care: Ritualism and the New Pyramid. Cheltenham, UK: Edward Elgar. doi.org/10.4337/9781847206855.

Braithwaite, V 2009. Defiance in Taxation and Governance: Resisting and Dismissing Authority in a Democracy. Cheltenham, UK: Edward Elgar. doi.org/10.4337/9781848449077.

Braithwaite, V and Ahmed, E 2005. 'A threat to tax morale: The case of Australia's higher education policy', Journal of Economic Psychology 26: 523-40. doi.org/10.1016/j.joep.2004.08.003.

Braithwaite, V and Wenzel, M 2008. 'Integrating explanations of tax evasion and avoidance', in A Lewis (ed.), Cambridge Handbook of PsychologyandEconomic Behaviour. Cambridge: Cambridge University Press, pp. 304-31. doi.org/10.1017/CBO9780511490118.013.

Braithwaite, V, Murphy, K and Reinhart, M 2007. 'Threat, motivational postures and responsive regulation', Law \& Policy 29: 137-58. doi. org/10.1111/j.1467-9930.2007.00250.x.

Grabosky, P 1995. 'Counterproductive regulation', International Journal of the Sociology of Law 23(4): 347-69. doi.org/10.1016/S01946595(05)80003-6. 
Granovetter, MS 1973. 'The strength of weak ties', American Journal of Sociology 78(6): 1360-80. doi.org/10.1086/225469.

Healy, J 2011. Improving Health Care Safety and Quality: Reluctant Regulators. Farnham, UK: Ashgate.

Jenkins, AL 1994. 'The role of managerial self-efficacy in corporate compliance with the law', Law and Human Behaviour 18(1): 71-88. doi.org/10.1007/BF01499145.

Meidinger, E 1987. 'Regulatory culture: A theoretical outline', Law EO Policy 9(4): 355-86. doi.org/10.1111/j.1467-9930.1987. tb00416.x.

Merton, RK 1968. Social Theory and Social Structure. New York: Simon \& Schuster.

Murphy, K 2004. 'The role of trust in nurturing compliance: A study of accused tax avoiders', Law and Human Bebaviour 28(2): 187-209. doi.org/10.1023/B:LAHU.0000022322.94776.ca.

Murphy, K 2005. 'Regulating more effectively: The relationship between procedural justice, legitimacy, and tax non-compliance', Journal of Law and Society 32(4): 562-89. doi.org/10.1111/j.14676478.2005.00338.x.

Parker, C and Braithwaite, J 2003. 'Regulation', in P Cane and MV Tushnet (eds), The Oxford Handbook of Legal Studies. Oxford: Oxford University Press, pp. 119-45.

Pettit, P 1997. Republicanism: A Theory of Freedom and Government. Oxford: Oxford University Press. 
This text is taken from Regulatory Theory: Foundations and applications, edited by Peter Drahos, published 2017 by ANU Press, The Australian National University, Canberra, Australia. 